\title{
Anesthetic Management of Scoliosis Correction in Mainzer-Saldino Syndrome: A Case Report
}

\author{
Diego Tavoletti ${ }^{1}$, Elisabetta Rosanò ${ }^{2}$, Elisabetta Cerutti ${ }^{2}$, Luca Pecora ${ }^{2}$
}

\section{Abstract}

Introduction: Mainzer-Saldino Syndrome is a rare autosomal recessive disease with mutations in genes that encode components involved in ciliary transport. This syndrome is characterized by chronic renal failure, severe retinal dystrophy and skeletal abnormalities including spinal and chest wall deformity resulting in severe respiratory failure.

Case presentation: We report the first successful anesthetic management of a 26-year-old man with Mainzer-Saldino Syndrome who underwent scoliosis deformity surgical correction. The severity of respiratory problems and renal dysfunction that characterize this syndrome require a multidisciplinary preoperative assessment and careful planning of intraoperative management, also in relation to surgical complications.

Conclusions: A careful preoperative assessment is essential for the correct anesthetic management. General anesthesia was safely administered; however a constant modulation of controlled ventilation is required to avoid barotrauma and an invasive hemodynamic monitoring is critical to allow adequate fluid management. Lastly, intraoperative dialysis can be planned in longlasting surgery with a significant loss and replacement of fluids.

Keywords: Mainzer-Saldino Disease; Ciliopathy; Anaesthesia

Introduction

Mainzer-Saldino Syndrome (MZSDS) is a rare genetic disorder that was first described in 1970 by Mainzer and Saldino, characterized by chronic renal failure, severe retinal dystrophy and skeletal abnormalities $[1]$.

A small number of individuals with this disorder have additional problems affecting other organs. These can include liver disease resulting in hepatic fibrosis, cerebellar ataxia, and mild intellectual disability.

It is a type of ciliopathy caused by altered cilia assembly, maintenance, or function with marked variability of clinical expression $[2,3]$.

We present the successful management of one case in a 26-year-old man posted for a scoliosis deformity correction.

Considering the insufficient data of such cases, we take this opportunity as a first description for a successful anesthetic management. Written informed consent was obtained from patient for this report.

\section{Case Report}

A 26-year-old male (weight $47.5 \mathrm{~kg}$; height $152 \mathrm{~cm}$ ) was proposed for a correction of a severe scoliosis deformity with a Cobb's angle curvature of $84^{\circ}$ (Fig. 1A). The patient underwent routine preoperative evaluation which included a complete physical and medical history, a 12 lead ECG and routine blood tests. He had a Class III Mallampati airway. Because of his scoliosis, pulmonary and cardiologic examinations were requested. Spirometry showed a severe restrictive pattern with a forced expiratory volume in $1 \mathrm{~s}$ and a forced vital capacity corresponding to $36 \%$ and $41 \%$ of the predicted values, respectively. In addition, the single-breath diffusion lung capacity for carbon monoxide showed a reduced diffusion capacity of $37 \%$ of predicted value. The cardiological examination showed a good hemodynamic compensation. Transthoracic echocardiography revealed a right atrium and ventricular sizes at upper limits of normal, minimal tricuspid regurgitation with a pulmonary artery systolic pressure of 43 $\mathrm{mmHg}$ and left ventricular ejection fraction of $60 \%$. The preoperative blood pressure and heart rate were normal. Blood tests revealed a serum creatinine of $8.27 \mathrm{mg} . \mathrm{dl}-1$. Considering his history of chronic renal failure and intermittent dialysis, an intraoperative hemodialysis was planned.

In the preoperative room, ECG and pulse oximetry were established and an arterial catheter was inserted into the radial artery under local anesthesia.

A FloTrac catheter (Edwards Lifesciences, Irvine, CA, USA) was connected to the intrarterial access and a EV1000/Volume View (Edwards Lifesciences, Irvine, CA, USA) for continuous arterial pressure, cardiac index (CI), stroke volume index, and stroke volume variation (SVV) monitoring.

Anesthesia induction was performed with fentanyl $100 \mathrm{mcg}$, propofol $80 \mathrm{mg}$ and cisatracurium $12 \mathrm{mg}$. Laryngoscopy and tracheal intubation were made with the aid of a video laryngoscope with no problems.

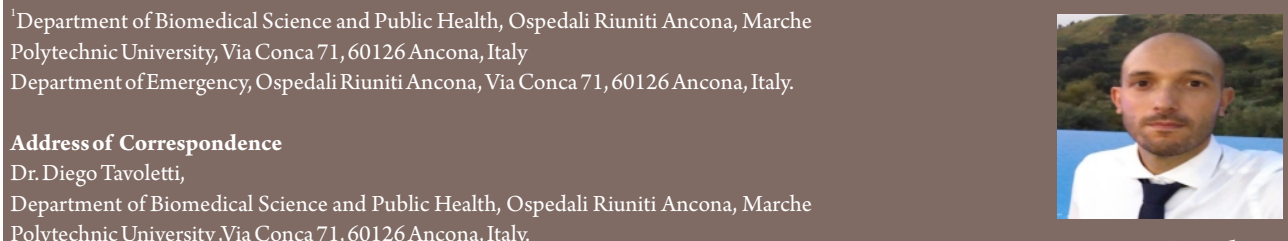

Polytechnic University,Via Conca 71, 60126 Ancona, Italy. E-mail: diego.tavoletti@libero.it
Dr. Diego Tavoletti

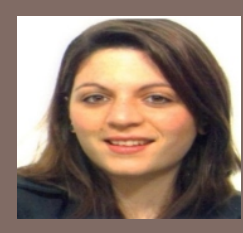

Dr. Elisabetta Rosanò

(C) 2020 by Journal of Anaesthesia and Critical Care Case Reports| Available on www.jaccr.com | DOI: 10.13107/jaccr.2020.v06i02.148

This is an Open Access article distributed under the terms of the Creative Commons Attribution Non-Commercial License (http://creativecommons.org/licenses/by-nc/3.0) which permits unrestricted non-commercial use, distribution, and reproduction in any medium, provided the original work is properly cited.

10 | Journal of Anaesthesia and Critical Care Case Reports | Volume 6 | Issue 2 | May-August 2020| Page 10-13 


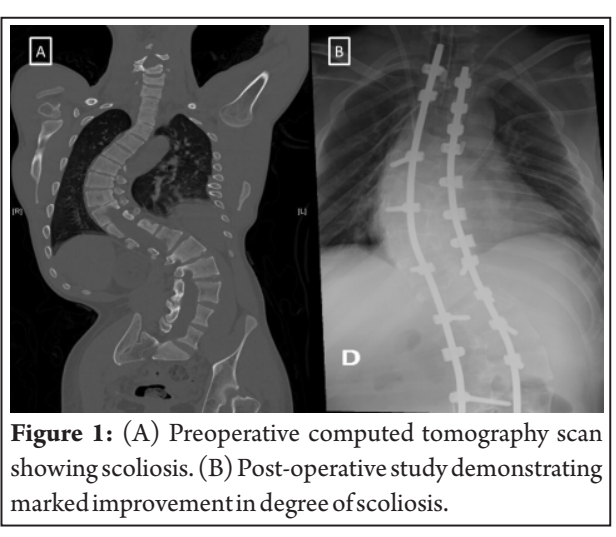

Intraoperative maintenance of anesthesia included total intravenous anesthesia (TIVA) with a combination of propofol and remifentanil.

A dual-lumen right internal jugular dialysis catheter and a dual-lumen left central venous catheter were inserted with an ultrasound guide. A chest radiograph was performed after catheters placement.

A Bispectral index (BIS) monitor was used to monitor the depth of anesthesia. The BIS value was mantained between 40 and 45 .

Cisatracurium bolus rate was titrated under the guidance of neuromuscular transmission monitoring.

Temperature monitoring was established with a single-use sensor placed on the patient's forehead. A warming system was positioned to ensure uniform convective warming.

The patient was placed in a prone position and attention has been paid to pressure areas. Tidal volume was mantained between 6-7 ml.kg-1 of predicted body weight with a plateau pressure at less than $28 \mathrm{cmH} 2 \mathrm{O}$.

The intraoperative fluid and vasopressor/inotrope administration were guided by the EV1000/Volume View parameters. The goal-directed fluid therapy was put in place to mantain SVV $<15 \%, \mathrm{CI}>$ 3,0 1.min-1.m2-1 and central venous pressure $<5 \mathrm{cmH} 2 \mathrm{O}$. Hemogasanalysis was performed every hour. He was transfused with five units packed red blood cell and five units fresh frozen plasma. A total of $2250 \mathrm{ml}$ of normal saline solution was administered during surgery.

The patient underwent dialysis for a total of 2 hours and 45 minutes. Urine production was absent and fluid was removed during hemodialysis.

The surgery proceeded uneventfully for 11 hours and 30 minutes. The surgical approach was a posterolateral arthrodesis from D2 to L5 with intraoperative neurophysiologic monitoring (Fig. $1 \mathrm{~B}$ ). At the end of the surgery, the patient was transferred to the ICU.

A good analgesic plan with opioids was managed. After an adequate weaning, the trachea was extubated the next day. Postoperative period was uneventful, vital signs and mental status were stable.

\section{Discussion}

MZSDS is a rare autosomal recessive disorder characterized by mutations in genes that encode components of the intraflagellar transport complex $\mathrm{A}$, which drives retrograde ciliary transport [4]. These genetic mutations cause abnormal function or formation of cell cilia that characterize a group of diseases called ciliopathies. These include a wide range of phenotypes resulting from developmental or functional defects of unique or multiple systems. The main features of ciliary disease are: retinal dystrophy, renal disease and cerebral anomalies. Additional manifestations include hepatic/pancreas fibrosis, diabetes, and skeletal dysplasia. Syndromic ciliopathies that affect bone development are classified as skeletal ciliopathies [2,3]. Primary clinical features of MZSDS are phalangeal coneshaped epiphyses, renal disease, severe retinal dystrophy, and hip abnormality [4]. In addition, the patient had severe scoliosis which resulted in restrictive respiratory failure. Pulmonary dysfunction due to chest deformity can be present in ciliopathies, especially in the Jeune syndrome, also called asphyxiating thoracic dystrophy $[5,6]$. These defects cause variations in normal physiology and can have anesthetic implications in the management of ciliopathies (Table 1).

For these reasons, our patient with MZSDS require a careful preoperative assessment.

Pulmonary function should be assessed through a physical examination, radiological investigation, and blood gas analysis. The presence of thoracic malformation could lead to lung restriction, so spirometry may be needed. In this case, a narrow chest associated with scoliosis resulted in severe restrictive ventilatory failure. During anesthesia, positive pressure ventilation could result in barotrauma or pneumothorax if peak airway pressure is not maintained as low as possible. Additionally, increased thoracic pressure can decrease venous return and diminish cardiac output [5].

Pressure-controlled ventilation has been suggested in Jeune syndrome patient [6].
In neurosurgery, the surgeon compresses and modifies the spine determining volume and pressure airway variations. Hence close collaboration is needed between the surgeon and the anesthesiologist. Based on the surgical stages and blood gas analysis, we alternated a volume-controlled and pressurecontrolled ventilation, maintaining a tidal volume of 6-7 ml.kg-1, a plateau pressure at less than $28 \mathrm{cmH} 2 \mathrm{O}$ and a low peak airway pressure.

So, MZSDS patient ventilation settings and regular blood gas analysis follow up are very important.

In addition, a careful airway assessment should be done preoperatively as facial bone deformities are present in ciliopathies.

Due to the limited literary knowledge of MZSDS and the pulmonary function anomalies described above, a preoperative cardiological evaluation with echocardiography would exclude any unknown cardiac malformations as well as right heart hypertrophy and pulmonary vascular hypertension. The latter two findings are typically present in patient with scoliosis.

Renal involvement has been noted in cilia disease. Progressive renal dysfunction results from a ciliary defect in the nephrons leading to end-stage renal disease. In this case, the patient reported a chronic renal failure with history of periodic dialysis treatments. Surgical arthrodesis from D2 to L5 leads to a significant intraoperative fluids loss and their replacement may be inappropriate, resulting in overload. For this reason and due to the moderate loss of fluids during this surgery, invasive hemodynamic monitoring is necessary to allow adequate fluid management. In this way, hemodynamics is optimized and the overload or deficit of circulating fluids is avoided. Furthermore, . in agreement with the nephrologist, we planned an intraoperative dialysis with a serial control of serum electrolytes.

Liver fibrosis may be present in MZSDS, but in our patient there were no clinical or laboratory findings of liver dysfunction.

In literature, which anesthetic drugs can safely be used in MZSDS is not described. However, in other ciliopathies such as Jeune syndrome, it is reported that non-inhaled anesthetics, inhaled anesthetics, and muscle relaxant able to be used safely $[5,6]$.

The complications of this type of surgery with the greatest impact are nerve injuries. For this reason, intraoperative strategies have 
been designed to reduce this risk. Somatosensory and corticomotor evoked potentials, that reflect the sensory and motor pathway functions respectively, were planned [7]. However, anesthetic agents and physiologic perturbations may interfere with somatosensory and corticomotor evoked potentials: hypothermia, hypotension, hypercapnia, halogen, and muscle blocking medication may interfere with the signal transmission [8]. Consequently, general anesthesia with proper depth control and without neuromuscular relaxation is a key for ideal management. The most highly recommended technique is TIVA avoiding neuro-muscular blocking during the anesthesia maintenance phase [9]. BIS helps to prevent the consequences of the anesthetic effect that could influence neurological monitoring directly and indirectly causing dynamic instability. It also helps to prevent the risk of intraoperative movements and awareness. Hypothermia increases bleeding in column surgery [10]. In this case, the body temperature was always under surveillance.

Finally, we believe that postoperative recovery in the ICU is useful for regular monitoring organ functions.

\section{Conclusion:}

a multidisciplinary team working is needed to perform a careful preoperative assessment and intraoperative management.

A detailed anesthetic plan is required in the perioperative period in MZSDS patient because the disorder can involve different organs. Several points must be considered including lung and renal function. General anesthesia was safely administered in our patient and controlled ventilation requires constant modulation by the anesthesiologist to avoid barotrauma. Intraoperative dialysis can be planned in long-lasting surgery with a significant loss and replacement of fluids.

\begin{tabular}{|c|c|c|}
\hline Ciliopathic Syndrome & Features & Anesthetic implications \\
\hline \multirow{6}{*}{ Bardet-Biedl Syndrome } & Obesity & Difficult airway management \\
\hline & Renal anomalies & Hemodynamic instability possible \\
\hline & Left ventricular hypertrophy & Avoid nephrotoxic drugs and fluid overload \\
\hline & Congenital heart disease & $\begin{array}{c}\text { Administer low doses of drugs with liver } \\
\text { metabolism }\end{array}$ \\
\hline & Hepatic fibrosis & \\
\hline & $\begin{array}{l}\text { High arched palate/dental } \\
\text { crowding/small teeth }\end{array}$ & \\
\hline \multirow{6}{*}{ Jeune Syndrome } & Chest wall deformity & $\begin{array}{l}\text { Avoid or use with caution drugs with liver } \\
\text { metabolism if liver disease is present or if } \\
\text { transaminases are increased. }\end{array}$ \\
\hline & Pulmonary hypoplasia & $\begin{array}{c}\text { Avoid high peak pressure during mechanical } \\
\text { ventilation. High thoracic pressure can decrease } \\
\text { venous return and cardiac output, barotrauma and } \\
\text { pneumothorax. }\end{array}$ \\
\hline & Pulmonary hypertension & \\
\hline & Fibrocystic liver disease & \\
\hline & Pancreatic insufficiency & \\
\hline & Renal anomalies & \\
\hline \multirow{2}{*}{ Nephronophthisis } & Renal anomalies & Avoid nephrotoxic drugs and fluid overload \\
\hline & Arterial hypertension & \\
\hline \multirow{3}{*}{ Joubert Syndrome } & $\begin{array}{l}\text { Cleft palate, large tongue, small jaw, } \\
\text { and laryngomalacia }\end{array}$ & Difficult airway management \\
\hline & $\begin{array}{l}\text { Abnormal breathing pattern } \\
\text { (hyperpnea/apnea) }\end{array}$ & Use opioids with caution \\
\hline & Hepatic fibrosis & $\begin{array}{l}\text { Avoid or use with caution drugs with liver } \\
\text { metabolism if liver disease is present or if } \\
\text { transaminases are increased }\end{array}$ \\
\hline \multirow[t]{2}{*}{ Meckel-Gruber Syndrome } & $\begin{array}{c}\text { Abnormality of } \\
\text { larynx/tongue/cervical vertebrae }\end{array}$ & Difficult airway management \\
\hline & Polycystic kidneys & Avoid nephrotoxic drugs and fluid overload \\
\hline \multirow[t]{2}{*}{ Oral-Facial-Digital Syndrome } & $\begin{array}{l}\text { High arched palate, poly-lobed } \\
\text { tongue, abnormalities of the } \\
\text { epiglottis and larynx }\end{array}$ & Difficult airway management \\
\hline & Congenital heart disease & \\
\hline \multirow{2}{*}{ McKusick-Kaufman Syndrome } & Congenital heart disease & Hemodynamic instability possible \\
\hline & Chronic renal failure & Avoid nephrotoxic drugs and fluid overload \\
\hline \multirow{6}{*}{ Alstrom Syndrome } & Obesity & Difficult airway management \\
\hline & Scoliosis & $\begin{array}{c}\text { Avoid high peak pressure during mechanical } \\
\text { ventilation. High thoracic pressure can decrease } \\
\text { venous return and cardiac output, barotrauma and } \\
\text { pneumothorax. }\end{array}$ \\
\hline & Restrictive lung disease & Avoid nephrotoxic drugs and fluid overload \\
\hline & Chronic renal failure & Hemodynamic instability possible \\
\hline & Dilated cardiomyopathy & $\begin{array}{c}\text { Avoid or use with caution drugs with liver } \\
\text { metabolism if liver disease is present or if } \\
\text { transaminases are increased }\end{array}$ \\
\hline & Hepatic dysfunction & \\
\hline
\end{tabular}

Table 1: Anesthetic concerns related to main diagnostic features of ciliopathies. 


\section{References}

1. Mainzer F, Saldino RM, Ozonoff MB, Minagi H. Familial nephropathy associated with retinitis pigmentosa, cerebellar ataxia and skeletal abnormalities. AmJMed. 1970;49:556-62.

2. Hildebrandt F, Benzing T, Katsanis N. Ciliopathies. NEngl.JMed. 2011;364:1533-43.

3. Waters AM, Beales PL. Ciliopathies: an expanding disease spectrum. Pediatr Nephrol. 2011;26:1039-56

4. Perrault I, Saunier S, Hanein S, Filho E, Bizet AA, Collins F, et al. Mainzer-Saldino Syndrome Is a Ciliopathy Caused by IFT140 Mutations. Am JHum Genet. 2012;90:864-70.

5. Borland LM. Anesthesia for children with Jeune's syndrome (asphyxiating thoracic dystrophy). Anesthesiology 1987;66:86-88.

6. Saletti D, Grigio TR, Tonelli D, Ribeiro Júnior OD, Marini F. Case report: anesthesia in patients with asphyxiating thoracic dystrophy: Jeune syndrome. Rev Bras Anestesiol.
$2012 ; 62: 424-31$.

7. Dawson EG, Sherman JE, Kanim LE, Nuwer MR. Spinal cord monitoring. Results of the Scoliosis Research Society and the European Spinal Deformity Society survey. Spine 1991;16:361-4.

8. Browning JL, Heizer ML, Baskin DS. Variations in corticomotor and somatosensory evoked potentials: effects of temperature, halothane anesthesia, and arterial partial pressure of $\mathrm{CO} 2$. Anesth Analg. 1992;74:643-8.

9. Sloan T, Rogers J. Dose and timing effect of etomidate on motor evoked potentials elicited by transcranial electric or magnetic stimulation in monkey and baboon.J Clin Monit Comput. $2009 ; 23: 253-61$.

10. Guest JD, Vanni S, Silbert L. Mild hypothermia, blood loss and complications in elective spinal surgery. Spine J. 2004;4:130-7.
Conflict of Interest: Nil

Source of Support: None

\section{How to Cite this Article}

Tavoletti D, Rosanò E, Cerutti E, Pecora L | Anesthetic Management of Scoliosis Correction in Mainzer-Saldino Syndrome: A Case Report | Journal of Anaesthesia and Critical Care Case Reports | May-August 2020; 6(2): 10-13. 